\title{
Relações de Gênero e Étnico-Raciais nos Currículos de Psicologia: Aproximações e Desafios
}

\author{
Andressa Carvalho ${ }^{1}$ \\ ${ }^{1}$ Universidade Federal do Rio Grande do Norte, RN, Brasil. \\ Carlivane Souza ${ }^{2}$ \\ ${ }^{2}$ Universidade Federal do Piauí, PI, Brasil. \\ João Paulo Macedo ${ }^{3}$ \\ ${ }^{3}$ Universidade Federal do Delta do Parnaíba, PI, Brasil.
}

\begin{abstract}
Resumo: Objetiva-se com este estudo investigar como os currículos dos cursos de Psicologia têm abordado as temáticas relacionadas a gênero, raça e etnia, considerando que tais elementos atravessam a constituição dos sujeitos e suas relações sociais. Trata-se de uma pesquisa documental a partir da análise dos Projetos Pedagógicos de Cursos (PPCs) de Psicologia no Brasil, disponíveis em domínio público. A amostra foi composta pelos PPCs que contivessem termos/expressões relacionados a estudos de gênero e étnico-raciais. Deste modo, a análise contou com 21 currículos, com o auxílio do software Iramuteq, a partir dos componentes textuais que incluíam as disciplinas, as ementas e as referências, produzindo, então, cinco perspectivas analíticas: Biológica, Psicologia Social, Estudos Antropológicos, Estudos Sociológicos e Estudos Interseccionais. Observamos a pluralidade de lentes teórico-epistemológicas nas quais se ancoram os estudos de gênero e étnico-raciais, situando-os em um espaço interdisciplinar, com maior prevalência para aqueles orientados pela Psicologia Social, pela Antropologia e pela Sociologia. O debate determinista sobre gênero, raça e etnia, com foco nas diferenças individuais, ainda presente, tem perdido espaço nos currículos. A perspectiva interseccional tem tido pouca expressão e está localizada em disciplinas optativas. Por fim, apontamos que há ainda grandes lacunas nos processos formativos no que tange a discussões sobre gênero e, particularmente, acerca das relações étnico-raciais, revelando um grande desafio para a Psicologia no cenário atual.
\end{abstract}

Palavras-chave: Formação em Psicologia, Gênero, Relações Étnicas e Raciais.

\section{Gender and Ethnical/Racial Relations in Psychology Curricula: Approximations and Challenge}

\begin{abstract}
This study investigated how the curriculum of Psychology courses have approached topics related to gender, race and ethnicity, considering that such elements go through the constitution of subjects and their social relations. It is a documentary research based on the analysis of the Psychology Courses Pedagogical Projects (PPCs) in Brazil, available in the public domain. The sample consisted of PPCs that contained keywords related to gender and ethnic/racial studies. Thus, twenty-one curricula were analyzed with help of Iramuteq, using textual components including disciplines, syllabuses and references, rendering five analytical perspectives: Biology, Social Psychology, Anthropological Studies, Sociological Studies and Intersectional Studies. We observed the plurality of theoretical-epistemological perspectives that ground both gender and ethnic-racial studies, placing them in an interdisciplinary space with more emphasis on studies guided by Social Psychology, Anthropology and Sociology. The deterministic debate about gender, race and ethnicity, focused on individual differences, has been supplanted in the curricula, as well as the intersectional perspective, found in optional
\end{abstract}


disciplines, which has not had much expression either. Lastly, we point out that there are still big gaps in formative processes regarding the discussions on gender and, particularly, about ethnic/ racial relations, revealing a great challenge for Psychology in the current scenario.

Keywords: Training in Psychology, Gender, Racial and Ethnic Relations.

\title{
Relaciones Étnico-Raciales y de Género en los Currículos de Psicología: Aproximaciones y Desafíos
}

\begin{abstract}
Resumen: Este estudio tuvo como objetivo investigar cómo los currículos de los cursos de Psicología han abordado las temáticas relacionadas a género, raza y etnia, considerando que estos elementos atraviesan la formación de los sujetos y sus relaciones sociales. Se trata de una investigación documental, basada en el análisis de los Proyectos Pedagógicos de Cursos de Psicología (PPC) en Brasil, disponibles en dominio público. La muestra fue compuesta por los PPC que contenían términos relacionados a los estudios de género y étnico-raciales. De este modo, se analizaron 21 currículos y se utilizó el software IRAMUTEQ, a partir de los componentes textuales relacionados a las disciplinas, a los temarios y a las referencias, produciendo cinco perspectivas analíticas: Biológica, Psicología Social, Estudios Antropológicos, Estudios Sociológicos y Estudios Interseccionales. Observamos la pluralidad de perspectivas teóricas y epistemológicas en los que se anclan los estudios de género y étnico-raciales, que los sitúan en un espacio interdisciplinario, con mayor prevalencia para aquellos orientados por la Psicología Social, Antropología y Sociología. El debate determinista sobre género, raza y etnia enfocándose en las diferencias individuales ha sido suplantado en los currículos, tampoco la perspectiva interseccional ha tenido mucha expresión, quedando marginada en disciplinas optativas. Por último, señalamos que todavía hay grandes brechas en los procesos formativos en lo que se refiere a las discusiones sobre género y, en particular, a las relaciones étnico-raciales, lo que revela un gran desafío para la Psicología en el escenario actual.
\end{abstract}

Palabras clave: Formación en Psicología, Género, Relaciones Raciales y Étnicas.

\section{Introdução}

Em meio à crise que atravessa a concepção de universidade e as saídas propostas para modernizá-la observam-se o aprofundamento de seu caráter instrumental e preocupações com a política de ciência, tecnologia, inovação e formação de recursos humanos que interessam ao mercado competitivo e a ordem capitalista mundial (Silveira \& Bianchetti, 2016). O caráter instrumental da universidade encontra força em outras duas grandes narrativas calcadas sob o solo da modernidade: a do progresso técnico e do progresso moral. A primeira está relacionada à função da universidade de produzir conhecimento científico e técnico para fornecê-lo às pessoas, transformando-o em conhecimento útil para atender aos interesses do mercado. Já a segunda narrativa diz respeito ao papel outorgado à universidade de educar moralmente a sociedade (Castro-Gómez, 2007).

Ademais, modernidade é aqui entendida em um sentido diferente da ideia de desenvolvimento e avanço em relação ao mundo primitivo. Relacionamos o termo com o momento em que a Europa passou a ser o centro da história mundial, sendo identificado com o início da colonização europeia nas Américas e a constituição dos países periféricos (Dussel, 2005). Pode ser inclusive identificado com Colonialidade, ou seja, forma como o poder do colonialismo moderno se manifesta, implicando o modo como se articulam conhecimento, trabalho e relações sociais, atravessados pelo capitalismo e pela ideia de raça (MaldonadoTorres, 2007), que encontra assento em um sistema triangular orientado pela colonialidade do poder, do saber e do ser. A colonialidade do saber encontra-se 
fundamentado na universidade enquanto instituição moderna, perpetuando uma atitude eurocêntrica frente ao conhecimento, a partir da qual o único conhecimento válido seria aquele científico, racional, produzido pela elite científica e filosófica europeia, herança do Iluminismo, deslegitimando as outras formas de conhecimento, que, a partir de então, tornamse pré-modernas ou primitivas (Ribeiro, 2017).

Nesses termos, a universidade cumpriu, historicamente, o papel de difusora dos ideais e dos valores da sociedade europeia, legitimando o conhecimento científico por ela produzido e influenciando diretamente o modo como tem sido construído o conhecimento ao redor do mundo. Na América Latina, a universidade seguiu os moldes europeus até meados do século passado, quando passou a sofrer as influências do modelo estadunidense, mas mantendo o caráter elitista e colonial tanto na estrutura como na produção de conhecimento. Nas últimas duas décadas, esse modelo de universidade tem sofrido muitas críticas, o que permitiu o surgimento de modelos contra-hegemônicos. Atualmente assiste-se à emergência da atitude decolonial na educação, com a problematização tanto do pressuposto de um conhecimento universal, resultante do colonialismo e do monoculturalismo ocidental, como também dos avanços neoliberais nas instituições de ensino (Estermann, Tavares, \& Gomes, 2017).

Em um país periférico, da metade Sul, como o Brasil, que traz em sua constituição as marcas do colonialismo, onde, conforme dados mais recentes do Censo, mais da metade da população é de mulheres (em torno de 51,5\%) e de negros (54\%) (Instituto Brasileiro de Geografia e Estatística, 2016), sendo que são sob esses grupos que incidem mais intensamente as inúmeras desigualdades sociais que historicamente têm atravessado o país, é tarefa urgente problematizar como as colonialidades do poder, do saber e do ser têm se articulado na sociedade brasileira. Alguns indicadores têm mostrado, por exemplo, como as mulheres negras com 15 anos ou mais apresentam uma taxa de analfabetismo maior do que as mulheres brancas, $10,2 \%$ contra $4,9 \%$, em 2015 ; e que as mulheres negras apresentam maior taxa de desocupação feminina, chegando a $13,3 \%$, contra $9,7 \%$ entre as mulheres brancas, superando a média feminina $(11,6 \%)$ e a masculina $(7,8 \%)$ (Instituto de Pesquisa Econômica Aplicada, 2017).

Partimos do debate de que raça, etnia e gênero são marcações sociais que se inscrevem nas vidas dos sujeitos, produzindo diversas ordens de exclusão e desigualdades sociais. Por esses termos, são categorias analíticas de suma importância para traçar reflexões e problematizações acerca da constituição das relações sociais em um país com uma herança colonial tão acentuada como o Brasil. Além disso, tais categorias são importantes operadores conceituais e analíticos para fornecer subsídios à formulação e implementação de políticas públicas voltadas para o combate das desigualdades sociais que atingem grande parte da população que vivencia aquelas marcações.

É nesse bojo que destacamos os chamados estudos de gênero e das relações étnico-raciais. Com relação aos estudos de gênero, sua emergência encontra-se imbricada com as lutas do movimento feminista em meados dos anos 1980 e 1990. As mulheres lutavam pela ruptura com o determinismo biológico, compreendendo que as diferenças entre homens e mulheres na estrutura social se estabelecem a partir de construções sócio-históricas, e não determinadas biologicamente pelas características sexuais (Louro, 2003). O gênero é assumido em seu aspecto relacional, descentrando-o do sujeito "mulher". Torna-se, então, além de um instrumento político de luta, uma importante ferramenta de análise das relações sociais que constituem os sujeitos (Scott, 1995).

No Brasil, os estudos de gênero ganharam visibilidade a partir da mobilização das mulheres a respeito da condição feminina na sociedade brasileira, influenciadas pelo movimento feminista nos Estados Unidos e na Europa, embora tenham encontrado resistência em se institucionalizar no espaço acadêmico, em razão da sua estreita relação com a política. Pode-se dizer que a inserção desses estudos no meio universitário se deu de forma marginal, por meio da pesquisa, e não do ensino, com a criação de Núcleos de Estudos sobre a Mulher e em cursos de pós-graduação, ou incluídas nas grades curriculares em disciplinas optativas, evidenciando que esta categoria de estudo tem sido tomada, em grande medida, por especialistas e por militantes do movimento feminista (Costa, 1994; Narvaz, 2009).

No campo dos estudos das relações étnico-raciais, um importante marco, fruto da luta do Movimento Negro, foi a Lei $n^{\circ} 10.639 / 2003$, que dispõe sobre a obrigatoriedade da inclusão do ensino da História e Cultura Afro-Brasileira nas grades curriculares de ensino tanto público como privado no país. Na década de 1980, o Movimento Negro, junto a 
outros segmentos da causa antirracista, promoveu um expressivo debate expondo o eurocentrismo presente nas práticas escolares, além de ter proposto mudanças nos currículos. Tais esforços foram finalmente reconhecidos pelo poder público com a implementação da Lei no 10.639 (Rocha \& Silva, 2013). Posteriormente, essa lei foi modificada pela Lei $n^{\circ} 11.645 / 2008$, passando a ser obrigatória também a inclusão da história e cultura indígena.

Embora tais leis não mencionem o ensino superior, o Parecer no 3/2004 e a Resolução no 1 / 2004 do Conselho Nacional de Educação (CNE), que instituem as diretrizes curriculares para a educação das relações étnico-raciais e para o ensino de história e cultura afro-brasileira e africana, deixam claro que tais diretrizes devem ser observadas em todos os níveis de ensino, inclusive no nível superior, com sua inclusão em conteúdos transversais nas disciplinas e em outras atividades curriculares.

Atualmente já se reconhece que gênero e raça, junto a outros marcadores sociais como classe, geração e localização geográfica, não podem ser analisados isoladamente, mas, sim, em suas intersecções. Tal constatação surgiu dentro do movimento feminista, a partir das críticas feitas por feministas negras, latino-americanas, africanas e de outras etnias, que denunciaram a insuficiência das questões até então enunciadas pelo feminismo, em razão do caráter universalista de gênero, que negligenciava as diferentes formas de opressão sobre a vida das mulheres (Santos, Carvalho, Amaral, Borges, \& Mayorga, 2016).

$\mathrm{O}$ termo interseccionalidade foi utilizado, originalmente, pela advogada feminista negra Kimberlé Crenshaw, em seu artigo "Mapping the Margins: Intersectionality, Identity Politics, and Violence against Women of Color", de 1991, em que traz à tona uma série de violências que incidiam especificamente sobre mulheres negras. A partir de então, esse conceito vem ganhando cada vez mais destaque enquanto importante ferramenta de análise das relações sociais e para a formulação de políticas públicas (Sardenberg, 2015). Os estudos interseccionais não indicam uma simples somatória de opressões sobre a vida das mulheres, mas apontam, sobretudo, para a necessidade de compreender como tais diferenças são produzidas, como elas se cruzam e produzem desigualdades (Mayorga, 2014).

Com esse mote, o presente artigo tem como objetivo analisar como os estudos de gênero e de relações étnico-raciais têm adentrado os currículos que orientam os processos formativos nos cursos de Psicologia do país. Alertamos que a ciência psicológica também foi um produto da Modernidade e, assim, constituiu-se sob os pilares do pensamento europeu ocidental, ao lado de outras ciências humanas e sociais, que se desenvolveu com base em práticas de observação e de descrição de comportamentos, com o objetivo de controlar, regular, disciplinar os corpos, comportamentos e saberes dos indivíduos, a fim de ajustá-los à ordem social capitalista. Nesse sentido, na Psicologia, historicamente revestida de concepções naturalizantes e individualizantes, gênero, raça, etnia e classe seriam pensados enquanto variáveis, e não como o centro da análise da constituição dos sujeitos (Narvaz, 2009).

O ano de 2018 foi eleito o Ano da Formação para a Psicologia, com o objetivo de revisar as Diretrizes Curriculares Nacionais para os cursos de graduação, organizado pela Associação Brasileira de Ensino em Psicologia (ABEP), pelo Conselho Federal de Psicologia (CFP) e pela Federação Nacional de Psicólogos (Fenapsi). A formação é considerada pelo CFP (2017) um espaço privilegiado para a construção de conhecimento, de saberes e de práticas, o que torna necessário que sejam apresentadas aos estudantes temáticas relevantes, de modo a fornecer elementos para uma leitura crítica da realidade e subsídios para as práticas interventivas, comprometendo-se, assim, com um exercício ético-político da profissão.

Assim, torna-se importante compreender que concepções, princípios e diretrizes têm norteado a construção dos projetos pedagógicos que orientam os cursos de graduação em Psicologia. Apoiamo-nos em Veiga-Neto (2002) ao considerar que os currículos refletem o contexto sob o qual se organizam, e que sua análise permite conhecer não somente os conteúdos que são importantes naquele contexto, mas sobretudo compreender a maneira como alguns conteúdos foram incluídos em detrimento de outros, ou seja, o que orientou tais escolhas. Assim, de maneira mais específica, pretende-se analisar nesse artigo como os currículos de graduação em Psicologia têm incluído as temáticas relativas a gênero, raça e etnia, compreendendo em que medida a formação vem contribuindo para a análise crítica desses múltiplos componentes que atravessam a constituição dos sujeitos.

\section{Método}

Trata-se de uma pesquisa documental com base na análise dos Projetos Pedagógicos de Cursos (PPCs) de graduação em Psicologia no Brasil que abordam 
em seus currículos temáticas relacionadas aos estudos de gênero e relações étnico-raciais.

A fonte de produção dos dados foi a base de dados do Ministério da Educação a respeito do Ensino Superior no Brasil, que indicou no Censo de 2017 a existência de 526 cursos de Psicologia, sendo 438 em instituições privadas e 88 em públicas (Brasil, 2017). Uma vez localizado nominalmente os cursos, independentemente do tipo de IES/categoria administrativa e local/região de funcionamento, realizou-se a busca dos PPCs, disponíveis em domínio público a partir da página eletrônica de cada IES e/ou por contato direto via $e$-mail institucional.

Esse trabalho de busca retornou 48 PPCs localizados. De posse das informações de cada PPC, foi elaborado um banco de dados com as informações mais gerais pertinentes aos cursos de graduação em Psicologia no Brasil, de maneira a traçar tanto o perfil dos cursos identificados quanto uma caracterização geral dos currículos a serem analisados (perfil do curso, princípios que orientam a formação em psicologia, perfil do aluno, objetivos do curso, matriz e ênfases curriculares), bem como possíveis conteúdos/temas relacionados ao campo dos estudos de gênero e relações étnico-raciais a partir das disciplinas ofertadas.

Em um primeiro momento, os PPCs foram analisados a partir de suas características gerais, como organização acadêmica, natureza jurídica, ano de início, turno e quantidade de vagas, informações sobre a região e o porte dos municípios onde se encontram localizados os cursos, como também seus componentes estruturantes, considerando seu corpo textual, assim como as disciplinas e suas características (período, obrigatória/optativa, ementa, referências, eixo comum/profissionalizante, carga horária, créditos). Para a análise das disciplinas, foi aplicado um filtro no conjunto das disciplinas e respectivas ementas e referências bibliográficas para localizar os componentes curriculares relacionados aos estudos de gênero e relações étnico-raciais. Para tanto, levaram-se em consideração os seguintes descritores: "gênero", "feminismo", "sexo", "sexualidade", "masculinidade", "feminilidade", "identidade de gênero", "LGBTQI", "gay", "homossexual", "lésbica", "travesti", "travestilidade", "transexualidade", "transgênero", "queer", "heteronormatividade", "intersexualidade", "direitos humanos", "direitos sexuais", "desigualdade de gênero", "violência", "violência de gênero", "violência sexual", "violência contra mulher", "raça", "etnia”, "diversidade étnica”, "diversidade racial", "negro", "negritude" "afrodescendência", "interseccionalidade", "racismo", "desigualdade racial", "exclusão racial", "preconceito racial", "discriminação", "intolerância", entre outros.

A análise foi auxiliada pelo software Iramuteq, que permite realizar análises textuais desde as mais simples, como a frequência de palavras, até as mais sofisticadas, como as multivariadas (Camargo \& Justo, 2013). Assim, o material foi organizado em um corpus construído a partir do título das disciplinas, das ementas e dos títulos das obras referenciadas. Tal corpus foi submetido ao método da classificação hierárquica descendente (CHD), um tipo de análise do Iramuteq que classifica os segmentos do texto em função de seus respectivos vocabulários. Esta análise visa obter classes de segmentos de texto que apresentam palavras semelhantes entre si e, ao mesmo tempo, diferentes das palavras de outras classes. Operacionalmente, o software organiza os dados em um dendograma, onde são ilustradas as classes e as relações entre elas, bem como permite visualizar aqueles segmentos de texto mais característicos de cada classe e sua posterior contextualização de acordo com a literatura (Camargo \& Justo, 2016). Por razões éticas, as universidades não serão identificadas.

\section{Resultados}

O trabalho de busca dos Projetos Pedagógicos dos Cursos de graduação em Psicologia, disponíveis em domínio público, na página eletrônica de cada uma das 526 instituições de ensino superior (IES), retornou com 54 projetos. Porém, ao aplicar o filtro com os descritores que tratam de relações de gênero e étnico-raciais, identificaram-se apenas 24 PPCs que apresentaram algum componente curricular ou menção no corpo do texto relacionado às temáticas aqui investigadas.

De forma geral, quanto à organização acadêmica dos cursos de Psicologia que abordam diretamente temas/conteúdos sobre relações de gênero e étnico-raciais, 14 são universidades, 6 faculdades e 4 centros universitários. Sobre a natureza jurídica, 13 cursos são de natureza privada, e 11 são públicos. Em relação à distribuição geográfica, são cursos presentes nas cinco regiões do país, com destaque para o Nordeste $(n=9)$. Além disso, 10 cursos estão localizados em capitais, e 14 em cidades do interior, sendo a maior parte destes em municípios de grande porte $(n=11)$. Quanto às demais características, observou-se que os cursos, em sua maioria, foram criados a partir de $2001(n=16)$, 
com oferta entre 81 e 100 vagas $(n=12)$, em regime integral $(n=13)$. A caracterização geral dos 24 currículos dos cursos de Psicologia analisados pode ser visualizada na Tabela 1.

Tabela 1

Caracterização geral dos PPCs.

\begin{tabular}{|c|c|c|}
\hline Características & $\mathrm{N}$ & $\%$ \\
\hline \multicolumn{3}{|l|}{ Organização acadêmica } \\
\hline Universidade & 14 & 58,4 \\
\hline Faculdade & 6 & 25 \\
\hline Centro universitário & 4 & 16,6 \\
\hline \multicolumn{3}{|l|}{ Natureza jurídica } \\
\hline Privado & 13 & 54,2 \\
\hline Público & 11 & 45,8 \\
\hline \multicolumn{3}{|l|}{ Região do país } \\
\hline Norte & 3 & 12,5 \\
\hline Nordeste & 9 & 37,5 \\
\hline Centro-Oeste & 3 & 12,5 \\
\hline Sudeste & 3 & 12,5 \\
\hline Sul & 6 & 25 \\
\hline \multicolumn{3}{|l|}{ Localização } \\
\hline Capital & 10 & 41,7 \\
\hline Interior & 14 & 58,3 \\
\hline \multicolumn{3}{|l|}{ Porte do município } \\
\hline Grande & 11 & 45,9 \\
\hline Médio-grande & 3 & 12,5 \\
\hline Médio & 3 & 12,5 \\
\hline Médio-pequeno & 3 & 12,5 \\
\hline Pequeno & 4 & 16,6 \\
\hline \multicolumn{3}{|l|}{ Ano de início } \\
\hline 1970-1990 & 3 & 12,5 \\
\hline $1971-2000$ & 5 & 20,8 \\
\hline 2001-dias atuais & 16 & 66,7 \\
\hline \multicolumn{3}{|l|}{ Turno } \\
\hline Integral & 13 & 54,2 \\
\hline Vespertino & 1 & 4,2 \\
\hline Noturno & 3 & 12,5 \\
\hline Matutino/Noturno & 5 & 20,8 \\
\hline Não informado & 2 & 8,3 \\
\hline \multicolumn{3}{|l|}{ Quantidade de vagas } \\
\hline Entre 30 e 50 & 5 & 20,9 \\
\hline Entre 51 e 80 & 7 & 29,1 \\
\hline Entre 81 e 100 & 12 & 50 \\
\hline
\end{tabular}

Com relação aos componentes estruturantes dos PPCs analisados, nota-se que, do total de 46 disciplinas identificadas com as temáticas aqui investigadas, a maioria está localizada no núcleo comum $(n=40)$, são de natureza teórica $(n=40)$, obrigatória $(n=30)$ e com carga horária que varia de 51 h a 72 h $(n=32)$. Foram identificadas seis disciplinas de natureza teórico-prática. Tais informações estão detalhadas na Tabela 2.

Tabela 2

Caracterização das disciplinas.

\begin{tabular}{lcc}
\hline \multicolumn{1}{c}{ Características } & $\mathrm{N}$ & $\%$ \\
\hline Modelo da disciplina & 40 & 87 \\
Teórico & 6 & 13 \\
Teórico-prático & & \\
Eixo & 40 & 87 \\
Núcleo comum (disciplinas básicas) & 4 & 8,7 \\
Núcleo profissionalizante (disciplinas & 4 & \\
de ênfase e estágio profissional) & & 4,3 \\
Não informado & 2 & \\
Tipo de disciplina & 30 & 65,2 \\
Obrigatória & 16 & 34,8 \\
Optativa & & \\
Carga horária (teórica) & 6 & 13 \\
17 h-50 h & 32 & 69,5 \\
51 h-72 h & 5 & 10,9 \\
73 h-150 h & 3 & 6,6 \\
Não informado & & \\
Carga horária (prática) & 5 & 10,9 \\
10 h-30 h & 1 & 2,2 \\
31 h-170 h & & \\
\hline
\end{tabular}

Além disso, também observamos que 10 PPCs apresentaram alguma informação sobre questões de gênero e relações étnico-raciais no decorrer do corpo textual do currículo, concentrando-se nos tópicos referentes a objetivos, perfil profissional (egresso), estágio e na concepção de curso que cada instituição estabelece para a graduação em Psicologia, inclusive fazendo alusão às Diretrizes Curriculares Nacionais para Educação das Relações Étnico-Raciais e para o Ensino de História e Cultura Afro-Brasileira e Indígena, incluindo-as como conteúdos disciplinares e nas atividades complementares temáticas relacionadas ao assunto. Embora tais currículos citem esses marcos legais, eles não aprofundam sob que perspectivas se sustentam as discussões 
ao longo do processo formativo e quais as implicações para o perfil profissional formado por tais instituições.

A segunda etapa da pesquisa consistiu na análise obtida por meio do Iramuteq. Entre os 24 PPCs que integraram a amostra inicial, 21 compuseram o corpus que foi analisado, e 3 foram excluídos desta etapa por não incluírem os recortes utilizados na pesquisa - gênero, raça e etnia - nas disciplinas. A partir da análise da CHD, o corpus considerou 75 segmentos de texto, ou seja, foram aproveitados $76,53 \%$ de segmentos para análise, satisfazendo o critério mínimo apontado pela literatura, que é de $75 \%$ de aproveitamento (Camargo \& Justo, 2016).

Para a formação das classes, o software utiliza o teste do qui-quadrado $\left(\chi^{2}\right)$, que indica o grau associativo entre as palavras e a sua respectiva classe $\left(\chi^{2}>3,84 ; \mathrm{p}<0,0001\right)$ (Souza, Wall, Thuler, Lowen, \& Peres, 2018). Com relação aos PPCs selecionados no corpus, a análise da CHD produziu cinco classes de segmentos de textos distintas, cada uma com seu respectivo valor percentual em relação ao total do corpus analisado, que podem ser visualizadas na Figura 1.

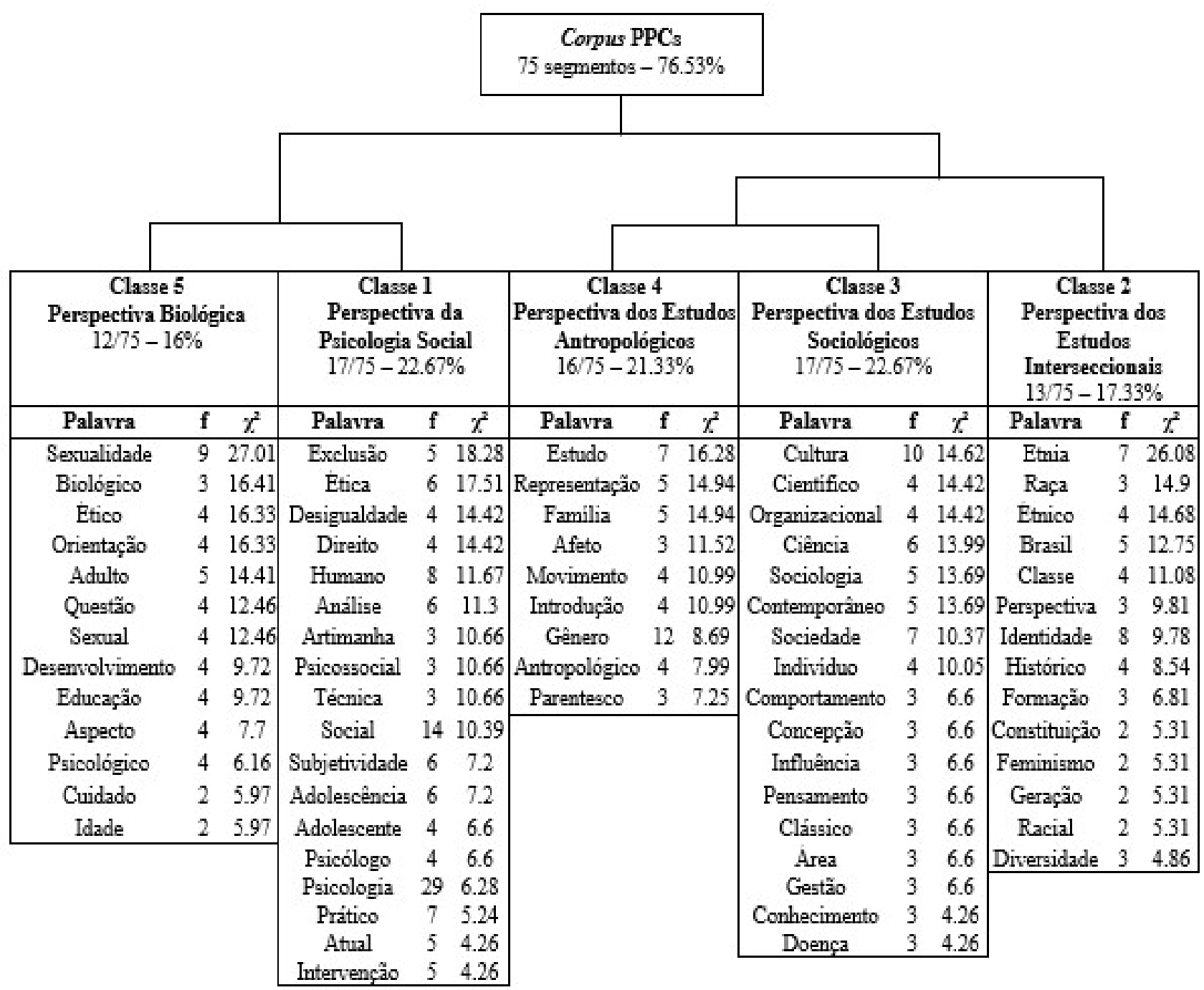

Figura 1

Dendograma da classificação hierárquica descendente (CHD) do corpus de PPCs.

Cada classe é composta pelas palavras com suas respectivas frequências (f) e a indicação do grau de significância, por meio da associação com o qui-quadrado $\left(\chi^{2}>3,84\right)$. Assim, cada classe contém as palavras mais representativas. Após o processamento dos dados pelo software, procedeu-se à leitura 
exaustiva de cada classe, apoiada pela literatura, a fim de compreendê-las e nomeá-las e, deste modo, seguir com a interpretação dos dados.

A classe 5, denominada Perspectiva Biológica, representa $16 \%$ dos segmentos de texto e comporta elementos relacionados a aspectos biológicos e do desenvolvimento humano, indicando a aproximação entre gênero e sexo biológico e as diferenças sexuais entre mulheres e homens, presentes nos estudos iniciais sobre a mulher. O PPC 7 é o que melhor representa esta classe $\left(\chi^{2}=16,33\right)$, lembrando que o grau de significância deve ser maior que 3,84 $\left(\chi^{2}>3,84\right)$. Este PPC traz em sua grade curricular duas disciplinas de caráter obrigatório, Sexualidade Humana e Orientação Profissional. A ementa da primeira disciplina é bem ilustrativa desta classe:

A sexualidade em diferentes sociedades e contextos históricos. Considerações gerais sobre a sexualidade humana. Aspectos biológicos e psicossociais do desenvolvimento da sexualidade humana na infância, adolescência, vida adulta e velhice. Educação sexual. Transtornos sexuais e da identidade de gênero: disfunções sexuais e parafilias. Aspectos profissionais e éticos no lidar com a sexualidade. Questões psicossociológicas na atualidade.

A classe 1, denominada Perspectiva da Psicologia Social, representa $22,67 \%$ dos segmentos de texto, e engloba palavras como exclusão, ética, desigualdade, direito e subjetividade, que remetem aos estudos em Psicologia Social, que é a área da Psicologia que melhor tem acolhido as questões de gênero (Santos et al., 2016) e as discussões sobre relações étnico-raciais (Martins, Santos, \& Colosso, 2013). Essa classe traz também as palavras psicólogo, psicologia, prático e intervenção, o que pode indicar a defesa de uma prática psicológica voltada para a atuação afinada ao debate sobre cidadania, a garantia de direitos de segmentos da população socialmente excluída e marginalizada, como, por exemplo, a população negra, e o desvelamento das desigualdades sociais.

OPPC $21\left(\chi^{2}=10,66\right)$ e o PPC $15\left(\chi^{2}=8,11\right)$ são os que mais se destacam na classe 1 . No PPC 21, as disciplinas, obrigatórias e de caráter teórico-práticas, estão voltadas a aspectos da atuação e intervenção psicológicas, tais como a disciplina "Estágio Específico I" e "Seminário de Práticas Psicológicas I”, e à área do trabalho, como a disciplina "Psicologia e Saúde do Trabalhador". Já o
PPC 15 traz a disciplina "Psicologia Social II", de caráter obrigatório, em cuja ementa observamos: "Temas atuais em psicologia social: exclusão social, direitos humanos e cidadania. Identidade e cultura. Gênero, relações de poder e violência; atuação do psicólogo social; a ética na psicologia social".

A classe 4 representa $21,33 \%$ dos segmentos de texto, e comporta elementos relacionados ao campo da Antropologia, como a presença das palavras parentesco, representação e família. Por isso, foi denominada Perspectiva dos Estudos Antropológicos, considerando que os estudos iniciais sobre mulheres nessa área estavam voltados aos estudos sobre família e parentesco (Sardenberg, 2004). O PPC 20, que melhor representa essa categoria $\left(\chi^{2}=8,47\right)$, traz o maior número de disciplinas que possuem relação com as temáticas de gênero e étnico-raciais no currículo ( $\mathrm{n}=8)$; porém, à exceção de uma, "Processos Psicológicos na Idade Adulta eVelhice", todas as outras são optativas na grade curricular.

Essas disciplinas optativas englobam temáticas fortemente relacionadas às teorias de base antropológica, como "Família e Parentesco e Sociedades Complexas", em cuja ementa visualizamos: "A perspectiva antropológica sobre família. Reprodução, sexualidade e parentesco. Papéis sexuais. Relações de gênero, família e sociedade. Teorias sobre parentesco e casamento. Parentalidade e conjugalidade. Casamento". Também o PPC 20 contempla uma disciplina voltada para os estudos étnicos - a saber, "Relações interétnicas" -, onde observamos a seguinte ementa: "Grupo étnico. Processos socioculturais de construção de identidades étnicas. Particularidades históricas e processos de diferenciação. Etnicidade e estrutura social. Antagonismo, discriminação e conflito racial. Status e mobilidade. Sociedades pluriétnicas, cultura e política".

A classe 3, denominada Perspectiva dos Estudos Sociológicos, aproxima-se da classe 4 , e representa $22,67 \%$ dos segmentos de texto, englobando palavras como cultura, científico, sociologia, contemporâneo, sociedade, indivíduo, que se relacionam às teorias clássicas da área da Sociologia. Os PPCs que melhor representam essa classe são o $18\left(\chi^{2}=13,69\right)$ e sua disciplina "Fundamentos das Ciências Sociais", obrigatória; e o $17\left(\chi^{2}=6,6\right)$, que apresenta as disciplinas "Psicologia Organizacional II" e "Bases Socioantropológicas da Psicologia”, ambas obrigatórias. A seguir, os trechos retirados das ementas ilustram a classe 3 : 
A Revolução Industrial, a Revolução Francesa e a influência para a construção do pensamento científico. A Sociologia como ciência. As primeiras abordagens na Sociologia moderna: Auguste Comte, Marx e Durkheim. Pós-modernidade, identidades e corporalidades. Antropologia como ciência e as origens da humanidade. A questão da Etnologia no Brasil (reflexão em torno da questão racial - a Multiculturalidade e as etnias como foco da formação cultural brasileira). Rituais e símbolos. Cultura e Sociedade. Cultura e personalidade. Temas contemporâneos de Antropologia. Antropologia, Sociologia e Psicologia: em busca da interdisciplinaridade (PPC 18).

Discussões sobre aspectos teóricos do corpo saúde e doença a partir dos sistemas médicos ocidentais. Doenças do ponto de vista dos profissionais de saúde e a construção cultural do paciente. Representações sociais da terapêutica, da cura e da morte. Aspectos simbólicos do corpo, da saúde e da doença. Antropologia e sociologia das emoções. Gênero, sexualidade e saúde. Tratar os conceitos de etnia, raça, identidade e diversidade étnica e racial. Relações sociais e novas tecnologias reprodutivas. Etnografia e metodologia qualitativa na área da saúde (PPC 17).

Por último, a classe 2, Perspectiva dos Estudos Interseccionais, representa $17,33 \%$ dos segmentos de texto, e as palavras que melhor representam esta classe estão relacionadas aos estudos que focam na perspectiva intercruzada de diferentes categorias analíticas, como gênero, raça e etnia, classe e geração, além de feminismo, diversidade e identidade, que caracterizam as discussões contemporâneas sobre tais categorias. O PPC $19\left(\chi^{2}=9,81\right)$, ilustrativo desta classe, traz a disciplina obrigatória Políticas Públicas, e na sua ementa: "Implicações da Teoria da Complexidade na perspectiva intercultural da educação. Múltiplas identidades (gênero, classe, etnia, geração) e suas relações com a educação".

Também o PPC $1\left(\chi^{2}=5,31\right)$ e o $4\left(\chi^{2}=4,83\right)$ relacionam-se a essa classe. O primeiro contempla duas disciplinas optativas, "Psicologia e Sexualidade" e "Psicologia e Etnias", ambas de caráter teórico-prático. Na primeira visualizamos a seguinte ementa: "Histórico da sexualidade. Desenvolvimento sexual. Aspectos psicológicos da sexualidade. Distúrbios da sexualidade. As parafilias. Educação sexual. Implicações éticas. O conceito de gênero e sua historicidade: gênero e movimentos sociais. Feminismo, Identidade, Estereótipos e diversidade". Por sua vez, a segunda disciplina situa os conteúdos na interface raça/etnia: "Concepções sobre raça e etnia. Identidade Étnica. Território, cultura e valores. A Psicologia e os povos indígenas. Preconceito e Estigma. População Negra. Aplicação".

O PPC 4 contempla duas disciplinas também de caráter optativo: Relações de Gênero e Tópicos em Cultura e Diversidade Etnicorracial. A primeira apresenta conteúdos relacionados a diversidade cultural, como, por exemplo: "Caminhos históricos da constituição das relações de gênero. As relações de gênero na cultura latino-americana e brasileira"; já na segunda, os conteúdos são "Cultura, diversidade, pluralismo, identidade e reconhecimento. Introdução à História e cultura africana e afro-brasileira. Cultura, artes e linguagens africanas e afro-brasileiras. Cultura, artes e linguagens indígenas".

\section{Discussão}

As categorias obtidas a partir do Iramuteq permitem observar as variadas perspectivas nas quais os estudos de gênero e relações étnico-raciais têm se ancorado nos currículos de Psicologia. Tais estudos situam-se em um campo analítico interdisciplinar e são atravessados por diversas lentes epistemológicas que implicam diferentes concepções teóricas, além de se referirem a categorias instrumentalizadas na luta política dos movimentos sociais, como o Feminismo e o Movimento Negro. Partindo das categorias, pode-se observar a preponderância das Perspectivas dos Estudos Antropológicos e Sociológicos, que constituem grandes áreas das Ciências Humanas e Sociais, e da Perspectiva da Psicologia Social, que juntas representam a maior parte das perspectivas apresentadas nos currículos (66,7\%). De maneira menos expressiva apareceram a Perspectiva dos Estudos Interseccionais (17\%) e a Perspectiva Biológica (16\%).

O gênero é um campo "marcado pela heterogeneidade epistemológica, teórica e metodológica" (Santos et al., 2016, p. 590), e essa pluralidade também reverberou nos cursos investigados, destacando-se as perspectivas: empiricista e de base essencialista; com base na socialização; e pós-moderna. Até meados do século XX predominou na Psicologia a primeira abordagem, essencialista, fundamentada nas diferenças 
entre os sexos, sendo que essas diferenças eram consideradas como inatas e estáveis, e deterministas na construção das personalidades (Borges, Canuto, Oliveira, \& Vaz, 2013). Nesse sentido, o termo gênero foi utilizado indistintamente do sexo biológico, e esse pressuposto predominou em grande parte das explicações psicológicas, implicando uma naturalização das diferenças entre homens e mulheres, por exemplo: características como afetividade e docilidade eram comumente utilizadas para qualificar as mulheres, enquanto aspectos como agressividade e racionalidade, os homens (Nogueira, 2001; Nuernberg, 2003). Pode-se observar tal perspectiva na expressividade dos termos sexualidade e biológico dentro da categoria Perspectiva Biológica. Contudo, a pequena representatividade de tal abordagem nos currículos pode indicar que as compreensões naturalizadas de gênero e as discussões centradas no fator da sexualidade e diferenças sexuais entre homens e mulheres estejam sendo cada vez mais superadas nos processos formativos em prol de outras perspectivas analíticas.

Outro ponto observado diz respeito à inserção de conteúdos relacionados aos transtornos das disfunções sexuais e de identidade de gênero e as parafilias nas ementas das disciplinas. Em razão do caráter fortemente normativo da Psicologia e a partir da visão essencialista, essa ciência esteve durante muito tempo preocupada em compreender a origem das diferenças sexuais e também dos chamados desvios da sexualidade, buscando fatores explicativos para a constituição das características masculinas e femininas no desenvolvimento da personalidade, e como tais desvios aparecem (Nuernberg, 2003). Seria necessário, pois, um aprofundamento acerca desses conteúdos disciplinares nos cursos investigados, no sentido de compreender se são discutidos desde uma perspectiva crítica, ou de modo a endossar a naturalização das características sexuais relacionadas a uma suposta personalidade normal.

Somente a partir do final da década de 1970 e dos anos 1980 a Psicologia começou a rever determinadas concepções naturalistas, essencialistas e dicotômicas, quando a vertente da Psicologia Social iniciou um movimento, no Brasil e na América Latina, de crítica à importação de modelos teórico-metodológicos dos Estados Unidos e da Europa, que ocasionou a chamada "crise da Psicologia Social". Foi a partir desse contexto que a Psicologia Social despontou como a área da Psicologia que melhor tem acolhido as questões de gênero (Santos et al., 2016). Tal fato pode estar relacionado com a ênfase dada à perspectiva dos Estudos em Psicologia Social, que está entre as categorias que mais sobressaíram na análise dos currículos de Psicologia, com conteúdos relacionados a processos psicossociais, como a exclusão.

Também se observa nos currículos analisados a grande influência de duas grandes matrizes de pensamento dentro das Ciências Humanas e Sociais: a Antropologia e a Sociologia. Com relação à primeira, tal influência pode ser explicada pelo pioneirismo desse campo em incluir o gênero como categoria analítica acerca da organização da sociedade e o modo de vida dos sujeitos, especialmente por meio dos estudos sobre parentesco e a constituição de diferentes sociedades (Nuernberg, 2003). Destaca-se a expressividade de conteúdos relacionados às teorias do parentesco e família nos currículos analisados, muito embora sejam insuficientes para explicar como o gênero é construído em sua complexidade, uma vez que outros elementos atravessam sua constituição, como a economia e a organização política (Scott, 1995).

Com relação à Sociologia, este campo tem recebido muitas críticas das teóricas feministas em razão ao apego às teorias sociais clássicas, que rejeitam as perspectivas feministas e manifestam uma resistência em incorporar novas perspectivas de análise, como os estudos culturais e pós-coloniais, o que reflete dificuldades em atualizar os currículos, desenhados muitas décadas atrás (Adelman, 2003). Tal rejeição relaciona-se com os preconceitos ainda existentes entre alguns pesquisadores sociais que tendem a minimizar a relevância dos estudos de gênero e feministas no conjunto de questões sociológicas e políticas mais amplas, inclusive rejeitando seu caráter científico. Ademais, alguns pesquisadores desse campo não se filiam ao movimento feminista por assumirem a categoria gênero como neutra e apolítica (Scavone, 2008).

Tal situação, inclusive, manifesta-se nos currículos com a presença dos termos ciência, científico e clássico nessa perspectiva; e nos conteúdos das disciplinas que abordam a construção do pensamento científico na modernidade a partir do advento das revoluções na Europa, na perspectiva do mito da modernidade (Dussel, 2005), a partir de pensadores clássicos da teoria social: Comte, Durkheim e Marx. Todavia, é importante destacar que há debates em torno de um projeto de sociologia feminista que tem feito avançar algumas questões nessa área 
em relação às teorias clássicas sociológicas, inclusive sob a crítica da ausência desse debate entre autores marxistas, apesar das controvérsias sobre o tema (Scavone, 2008).

Sobre as relações étnico-raciais, a Antropologia Física e a Biologia utilizaram o conceito de raça, inaugurado pelas ciências naturais, para qualificar a espécie humana, legitimando a hierarquização das raças com base nos traços físicos e qualidades psicológicas, morais e supostamente intelectuais (Munanga, 2003). Inicialmente, a Psicologia também serviu para legitimar as diferenças entre raças. No Brasil, a aliança entre esta ciência e a Medicina produziu investigações que associavam determinadas características étnico-raciais com tipos de caráter, inclusive atribuindo-se certas formas de doença mental como típicas de determinadas etnias e raças (Santos, Schucman, \& Martins, 2012).

No geral, os resultados dessa investigação indicam que, embora a Psicologia tenha avançado na construção de aportes teóricos relacionados ao racismo e suas implicações psicológicas para os sujeitos, além de uma maior proximidade com os movimentos de luta contra a discriminação racial, esta ciência ainda está muito aquém quando se trata da produção de conhecimento acerca das relações étnico-raciais e da inserção desse conteúdo nas matrizes curriculares dos cursos no Brasil (Schucman, Nunes, \& Costa, 2017).

Além disso, observou-se que as categorias gênero e raça/etnia aparecem abordadas de forma separada na maior parte das disciplinas, o que pode indicar que a perspectiva que considera as interseccionalidades tem adentrado os currículos de Psicologia de forma ainda muito tímida. Como foi observado no presente estudo, entre os três currículos que integram a categoria Perspectiva dos Estudos Interseccionais, apenas uma disciplina aparece como obrigatória, contemplando a discussão das identidades, embora esteja relacionada a educação. As demais disciplinas, que contemplam discussões de gênero, raça, etnia, classe e geração, sobre diversidade, cultura e movimentos sociais, são de caráter optativo, o que contribui para marginalizar tais estudos dentro dos currículos.

\section{Considerações finais}

Este estudo teve como foco analisar como as discussões sobre gênero e relações étnico-raciais têm se inserido nos currículos dos cursos de Psicologia, o que permitiu observar as múltiplas perspectivas teóricas e epistemológicas que têm orientado tais discussões. De modo geral, percebeu-se que ainda há uma marginalização refletida em conteúdos abordados em disciplinas optativas, especialmente no tocante aos estudos étnico-raciais, com pouca expressão nos currículos em geral. Embora abordagens de gênero que ainda reproduzem hierarquias e diferenças individuais pautadas em um modelo biológico venham sendo superadas, elas estão inseridas em disciplinas obrigatórias, enquanto o debate atual das interseccionalidades tem pouca expressão nos currículos, localizado em disciplinas optativas. Além disso, houve maior expressão da área da Psicologia Social, o que nos faz questionar se as demais áreas da Psicologia podem prescindir das análises de gênero e das relações étnico-raciais.

Dessa forma, reforçamos as indagações de Narvaz (2009) sobre quais projetos de sociedade, de universidade e de Psicologia estamos produzindo e queremos produzir, uma vez que os discursos hegemônicos construídos pelos saberes psicológicos serão (re)produzidos e incorporados nas práticas e na formação em Psicologia. Romper com os pilares da Modernidade/Colonialidade e outros conservadorismos em que se fundamentou a Psicologia, enquanto projeto científico e com os componentes epistemológicos e teórico-práticos que têm legitimado as hierarquias sociais e orientado seus processos formativos, constitui um grande desafio a fim de promover uma verdadeira atitude decolonial (Castro-Gómez, 2007), mas também feminista, na Psicologia.

Torna-se, portanto, imprescindível (re)construir processos formativos que possibilitem compreender as dinâmicas das relações de poder nas quais os diversos marcadores sociais (gênero, raça, etnia, entre outros) vão se articulando na constituição dos sujeitos e de suas relações sociais, assim como também produzem desigualdades. Deste modo, poderíamos combater os essencialismos e naturalizações que historicamente marcaram a ciência psicológica, e construir práticas mais afinadas com um projeto ético-político que valorize os múltiplos modos de existência e as necessidades da população brasileira e latino-americana. 


\section{Referências}

Adelman, M. (2003). Das margens ao centro? Refletindo sobre a teoria feminista e a sociologia acadêmica. Revista Estudos Feministas, 11(1), 284-288. https://dx.doi.org/10.1590/S0104-026X2003000100020

Amâncio, L. (2001). O género na psicologia: uma história de desencontros e rupturas. Psicologia, 15(1), 9-26. http://www.scielo.mec.pt/scielo.php?script=sci_arttext\&pid=S0874-20492001000100001\&lng=pt\&tlng=pt

Borges, L. S., Canuto, A. A., Oliveira, D. P., \& Vaz, R. P. (2013). Abordagens de gênero e sexualidade na psicologia: Revendo conceitos, repensando práticas. Psicologia Ciência e Profissão, 33(3), 730-745. http://dx.doi.org/10.1590/S1414-98932013000300016

Camargo, B. V., \& Justo, A. M. (2013). IRAMUTEQ: Um software gratuito para análise de dados textuais. Temas em Psicologia, 21(2), 513-518. http://dx.doi.org/10.9788/TP2013.2-16

Camargo, B.V., \& Justo, A. M. (2016). Tutorial para uso do software de análise textual IRAMUTEQ.http://www.iramuteq. org / documentation/fichiers/tutoriel-en-portugais

Castro-Gómez, S. (2007). Decolonizar la universidad: La hybris del punto cero y el diálogo de saberes. In S. CastroGómez \& R. Gosfroguel (Orgs.), El giro decolonial: reflexiones para una diversidad epistémica más allá del capitalismo global (pp. 79-91). Bogotá: Siglo del Hombre Editores. http://www.unsa.edu.ar/histocat/hamoderna/ grosfoguelcastrogomez.pdf

Conselho Federal de Psicologia. (2017). Relações raciais: Referências técnicas para atuação de psicólogas/os. Brasília, DF: CFP.

Costa, A. (1994). Os estudos da mulher no Brasil ou a estratégia da corda bamba. Revista Estudos Feministas, 401, 401-409. https://periodicos.ufsc.br/index.php/ref/article/view/16172/14723

Dussel, E. (2005). Europa, modernidade e eurocentrismo. In E. Lander, A colonialidade do saber: eurocentrismo e ciências sociais. Perspectivas latino-americanas (pp. 25-34). Buenos Aires: Clacso. http://biblioteca.clacso.edu.ar/gsdl/ collect/clacso/index/assoc/D1200.dir/5_Dussel.pdf

Estermann, J., Tavares, M., \& Gomes, S. (2017). Interculturalidade crítica e decolonialidade da educação superior: para uma nova geopolítica do conhecimento. Laplage em Revista, 3(3), 17-29. https://doi.org/10.24115/S2446-6220201733375p.17-29

Instituto Brasileiro de Geografia e Estatística. (2016). Pesquisa nacional por amostra de domicílios: síntese de indicadores. Rio de Janeiro, RJ: IBGE.

Instituto de Pesquisa Econômica Aplicada. (2017). Retrato das desigualdades de gênero e raça. Brasília, DF: Ipea. http://www.ipea.gov.br/portal/images/stories/PDFs/170306_retrato_das_desigualdades_de_genero_raca.pdf

Louro, G. L. (2003). Gênero, sexualidade e educação: uma perspectiva pós-estruturalista. Petrópolis, RJ:Vozes.

Maldonado-Torres, N. (2007). Sobre la colonialidad del ser: contribuciones al desarrollo de un concepto. In S. Castro-Gómez \& R. Grosfoguel (Orgs.), El giro decolonial: reflexiones para una diversidad epistémica más allá del capitalismo global (pp. 127-167). Bogotá: Siglo del Hombre Editores. http://www.unsa.edu.ar/histocat/hamoderna/grosfoguelcastrogomez.pdf

Martins, E., Santos, A., \& Colosso, M. (2013). Relações étnico-raciais e psicologia: publicações em periódicos da SciELO e Lilacs. Revista Psicologia: Teoria e Prática, 15(3), 118-133. http://pepsic.bvsalud.org/ scielo. php?script=sci_arttext\&pid=S1516-36872013000300009\&lng=pt\&tlng=pt

Mayorga, C. (2014). Algumas contribuições do feminismo à psicologia social comunitária. Athenea Digital, 14(1), 221-236. https://doi.org/10.5565/rev/athenead/v14n1.1089

Munanga, K. (2003). Uma abordagem conceitual das noções de raça, racismo, identidade e etnia. https://www.geledes.org.br/wp-content/uploads/2014/04/Uma-abordagem-conceitual-das-nocoes-de-racaracismo-dentidade-e-etnia.pdf

Narvaz, M. G. (2009). A(in)visibilidade do gênero na psicologia acadêmica: onde os discursos fazem(se) política (Dissertação de mestrado). Universidade Federal do Rio Grande do Sul, Porto Alegre, RS.

Nogueira, C. (2001). Feminismo e discurso do género na psicologia social. Psicologia \& Sociedade, 13(1), 107-128. http://hdl.handle.net/1822/4117 
Nuernberg, A. H. (2003). Gênero no contexto da produção científica brasileira em psicologia (Tese de doutorado). Universidade Federal de Santa Catarina, Florianópolis, SC. http://repositorio.ufsc.br/xmlui/handle/123456789/86384

Ribeiro, D. (2017). Decolonizar a educação é possível? A resposta é sim e ela aponta para a educação escolar quilombola. Identidade!, 22(1), 42-56. de 2018, de http:// periodicos.est.edu.br/index.php/identidade/article/view/2985/2878

Rocha, S., \& Silva, J. (2013). À luz da Lei 10.639/03, avanços e desafios: movimentos sociais negros, legislação educacional e experiências pedagógicas. Revista da Associação Brasileira de Pesquisadores/as Negros/as (ABPN), 5(11), 55-82. http://abpnrevista.org.br/revista/index.php/revistaabpnl/article/view/189

Santos, A., Schucman, L. V., \& Martins, H. V. (2012). Breve histórico do pensamento psicológico brasileiro sobre relações étnico-raciais. Psicologia Ciência e Profissão, 32(esp), 166-175. https://dx.doi.org/10.1590/S1414-98932012000500012

Santos, L. C., Carvalho, A. B., Amaral, J. G., Borges, L. A., \& Mayorga, C. (2016). Gênero, feminismo e Psicologia Social no Brasil: análise da revista Psicologia \& Sociedade (1996-2010). Psicologia \& Sociedade, 28(3), 589-603. https:// dx.doi.org/10.1590/1807-03102016v28n3p589

Sardenberg, C. M. (2004). Estudos feministas: esboço crítico. In C. G. Amaral (Org.), Teoria e práxis dos enfoques de gênero (pp. 17-40). Salvador, BA: Negif. http://www.repositorio.ufba.br/ri/handle/ri/6880

Sardenberg, C. M. (2015). Caleidoscópios de gênero: gênero e interseccionalidades na dinâmica das relações sociais. Mediações, 20(2), 56-96. http://dx.doi.org/10.5433/2176-6665.2015v20n2p56

Scavone, L. (2008). Estudos de gênero: uma sociologia feminista? Revista Estudos Feministas, 16(1), 173-186. http://dx.doi.org/10.1590/S0104-026X2008000100018

Schucman, L. V., Nunes, S., \& Costa, E. S. (2017). A Psicologia da Universidade de São Paulo e as relações raciais: perspectivas emergentes. Psicologia USP, 28(1), 144-158. https://dx.doi.org/10.1590/0103-6564a20132413

Scott, J. (1995). Gênero: uma categoria útil de análise histórica. Educação \& Realidade, 20(2), 71-99. (Trabalho original publicado em 1988). http://seer.ufrgs.br/index.php/educacaoerealidade/article/view/71721/40667.

Silveira, Z. S., \& Bianchetti, L. (2016). Universidade moderna: dos interesses do Estado-nação às conveniências do mercado. Revista Brasileira de Educação, 21(64), 79-99. http://dx.doi.org/10.1590/S1413-24782016216405

Souza, M. A. R., Wall, M. L., Thuler, A. C. M. C., Lowen, I. M. V., \& Peres, A. M. (2018). O uso do software IRAMUTEQ na análise de dados em pesquisas qualitativas. Revista da Escola de Enfermagem da USP, 52, 1-7. https://dx.doi.org/10.1590/s1980-220x2017015003353

Veiga-Neto, A. (2002). Cultura e currículo. Contrapontos, 2(1), 43-51. https://siaiap32.univali.br/seer/index.php/rc/ article/view/133/113

\section{Andressa Carvalho}

Graduada e mestre em Psicologia pela Universidade Federal do Piauí, doutoranda em Psicologia pela Universidade Federal do Rio Grande do Norte, Natal - RN. Brasil.

E-mail: dressacarvalho7@gmail.com

(1) https://orcid.org/0000-0003-2721-7472

\section{Carlivane Souza}

Graduanda em Psicologia pela Universidade Federal do Piauí, Teresina - PI. Brasil.

E-mail: carlivane.sj@hotmail.com

(1) https://orcid.org/0000-0001-5882-6380

\section{João Paulo Macedo}

Mestre e doutor em Psicologia pela Universidade Federal do Rio Grande do Norte. Bolsista Produtividade do CNPQ. Professor dos Programas de Pós-Graduação em Psicologia da Universidade Federal do Delta do Parnaíba, Parnaíba - PI, e da Universidade Federal do Ceará, Fortaleza - CE. Brasil.

E-mail: jpmacedo@ufpi.edu.br

(1) https://orcid.org/0000-0003-4393-8501 
Endereço para envio de correspondência:

Universidade Federal do Delta do Parnaíba - UFDPar. Av. São Sebastião, 2819, São Benedito. CEP: 64202-020.

Parnaíba - PI. Brasil.

Recebido 02/06/2018

Aceito 05/04/2019

Received 06/02/2018

Approved 04/05/2019

Recibido 02/06/2018

Aceptado 05/04/2019

Como citar: Carvalho, A., Souza, C., \& Macedo, J. P. (2020). Relações de Gênero e Étnico-Raciais nos Currículos de Psicologia: Aproximações e Desafios. Psicologia: Ciência e Profissão, 40, 1-14.

https://doi.org/10.1590/1982-3703003201972

How to cite: Carvalho, A., Souza, C., \& Macedo, J. P. (2020). Gender and Ethnical/Racial Relations in Psychology Curricula: Approximations and Challenges. Psicologia: Ciência e Profissão, 40, 1-14.

https://doi.org/10.1590/1982-3703003201972

Cómo citar: Carvalho, A., Souza, C., \& Macedo, J. P. (2020). Relaciones Étnico-Raciales y de Género en los Currículos de Psicología: Aproximaciones y Desafíos. Psicologia: Ciência e Profissão, 40, 1-14.

https://doi.org/10.1590/1982-3703003201972 